\title{
Biological investigations on the role of hydrogel formulations containing bioactive natural agents against some common phytopathogens of Phaseolus vulgaris L. and seed germination
}

\author{
Hazem S. Elshafie, Maria Nuzzaci, Giuseppina Logozzo, Tania Gioia, Ippolito Camele \\ School of Agricultural, Forestry, Food and Environmental Sciences (SAFE), University of Basilicata, Potenza, Italy
}

\begin{abstract}
Recent scientific research have manipulated the use of hydrogel in seed coating technology based on synthetic and chemical additives. The current study has been carried out to evaluate the biological activity of new seed coating formulations containing hydrogel based on natural substances or beneficial microorganisms on seed germination and controlling some common diseases of Phaseolus vulgaris L. New formulations have been prepared as single mixtures of hydrogel with the following bioactive substances: i) oregano Essential Oil (org EO); ii) Ornithine Lipid (OL); and two microorganisms i) Burkholderia gladioli and ii) Trichoderma harzianum T22. Results revealed that, the hydrogel formulation based org EO showed the highest significant activity against the majority of tested phytopathogens in a dose dependent manner. Regarding the antagonistic microbial activity, results showed that hydrogel formulations based T. harzianum T22 and $B$.
\end{abstract}

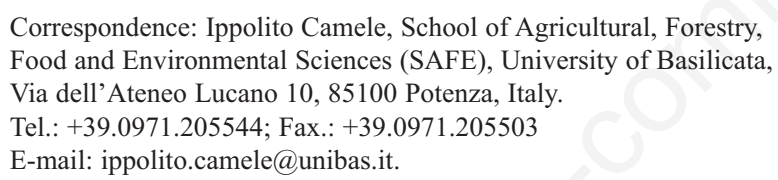

Key words: Seed coating; plant systemic resistance; antimicrobial effect; antagonistic activity; secondary metabolites.

Funding: This research was financially supported by a grant from PSR Basilicata 2014/2020 - Sottomisura 10.2 "Conservazione e uso sostenibile delle risorse genetiche in agricoltura" project: PHAS.G.Re.En Conservazione e Uso Sostenibile di Risorse Genetiche di Fagiolo (Phaseolus vulgaris L.) Lucano. DGR n.277 del 04/04/2017 n.00382520427.

Conflicts of interest: The authors declare no conflict of interest.

Received for publication: 30 June 2020.

Accepted for publication: 21 August 2020.

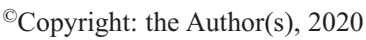

Licensee PAGEPress, Italy

Journal of Biological Research 2020; 93:9219

doi:10.4081/jbr.2020.9219

This article is distributed under the terms of the Creative Commons Attribution Noncommercial License (by-nc 4.0) which permits any noncommercial use, distribution, and reproduction in any medium, provided the original author(s) and source are credited. gladioli were able to significantly reduce the growth of the majority of tested phytopathogens. In addition, the highest significant percentage of seed germination has been achieved using the formulations of B. gladioli and org EO. Regarding the disease incidence suppression assay, results explicated that org EO and OL were able to significantly inhibit the fungal disease incidence on $P$. vulgaris seeds steadily depending on the tested concentrations. In conclusion, the use of natural bioactive substances in hydrogel formulation would greatly reduce dependence on chemical pesticides and hence decreasing the environmental pollution and eventual harmful effects on plant, animal and human health.

\section{Introduction}

Nowadays, it is strongly advisable to increase the crop production in parallel with protecting environment as well as human, animal and plant health due to the huge increase in human population. The control of different common and serious phytopathogens is one of the most interesting strategies in food safety. The biological function of seed is a protection-reservoir for the nutrition of the new embryo. ${ }^{1}$ The biochemical properties of seed can have an effect on plant performance and its resistance to unfavorable environmental conditions, climatic changes and severe phytopathogens. No doubt that the reduction of seed-germination percentage and seedling establishment can be a reason for seed infection by different phytopathogens.

One of the most promising measurements for plant protection is seed coating before sowing and planting by using pesticides. Seed coating is a technique in which several substances such as nutrients or pesticides can be added to the seeds in adhesive agents such as hydrogel or soft agar to enhance their germination and improve seedlings performance. ${ }^{2}$ The possible additives are fertilizers, moisture attractive, growth regulators, microorganisms and pesticides. The rationality of the current research is to protect the health of Phaseolus vulgaris L. and improve its performance throughout seed coating technology with some natural bioactive substances inoculated in hydrogel formulation.

Regarding the antagonistic activity, a wide range of different microorganisms have biological control activities either through antagonizing pathogen development or eliciting a plant-mediated resistance response. Many bacteria are able to produce different bioactive secondary metabolites such as antibiotics and cell-wall degrading enzymes as well as Volatile Organic Compounds (VOCs) among them Burkholderia spp. ${ }^{3}$ Several research studies have clearly indicated the biological efficacy of Burkholderia gladioli Zopf (Yabuuchi) (3,4 $^{3}$ as well as its secondary metabolites against different phytopathogens. ${ }^{3-5}$ Elshafie et $a l .{ }^{4}$ reported that 
the potential biological activity of some strains of B. gladioli could be correlated to their ability to produce lipoamino acids especially lipodepsipeptide. In particular, Ornithine Lipids (OLs) are phosphorus-free membrane lipids, probably found in membranes of both Gram-negative (G-ve) and some Gram-positive (G+ve) bacteria, and it seemed to have been enriched in the outer membrane. ${ }^{6}$ OLs showed diverse biological effects in microorganisms and mammals. ${ }^{6}$

It has also been documented that OLs and their hydroxylated forms are important for plant-microbe interactions where the plant is able to recognize OL or hydroxy-OL leading to an earlier plant defense response. ${ }^{7}$ In addition, OLs play an essential role during the symbiosis of Rhizobium tropici with common bean (P.vulgaris) as reported by Siebers et al. ${ }^{7}$ Plant response might also be abolished and the disease infection could be accelerated in the absence of bacterial OL or hydroxy-OL. Several studies have reported the positive effect of L-ornithine application on the growth of seedlings and concluded that the fresh weight, root length and germination percentage have shown insignificant values to untreated control seedlings. ${ }^{7}$ Therefore, the use of OL in a hydrogel formulation could has promising biological effects against many common diseases of P. vulgaris. ${ }^{7}$

On the other hand, Trichoderma spp. Pers. plays an important role in plant growth. Trichoderma have also the ability to produce different secondary metabolites including peptaibols, polyketides, pyrones, terpenes, polypeptides and some extracellular hydrolytic enzymes. ${ }^{8}$

The current study also focuses on the use of plant Essential Oils (EOs) incorporated with hydrogel formulation to evaluate their possibility as natural alternatives to chemical antimicrobial substances. ${ }^{9,10}$ In this context, the use of plant EOs as possible natural alternatives to chemical pesticides is recently being encouraged and becoming a target of interest for many Applied Research Organizations, especially in Europe by the directive 2009/128/CE, which aims to lower the dependency on chemical pesticides and hence reduce environmental pollution and eventual harmful effects on plant, animal and human health. ${ }^{11}$

In particular, the current research relied mainly on preparing the following new formulations as mixtures of hydrogel with some bioactive substances: i) oregano Essential Oil (org EO) and ii) Ornithine Lipid (OL); or two beneficial antagonizing microorganisms: i) Burkholderia gladioli and ii) Trichoderma harzianum T22.

The following in vitro biological assays have been carried out i) the effect of new hydrogel formulations on the seed germination of P. vulgaris; ii) antifungal activity against Fusarium oxysporum von Schlechtendal, Rhizoctonia solani (Cooke) Wint., Sclerotinia sclerotiorum (Lib.) de Bary, Penicillium expansum Link and
Aspergillus flavus Link; iii) antibacterial activity against Clavibacter michiganensis Corrig. (Smith) Davis, Xanthomonas phaseoli var. fuscans (Burkholder) Starr \& Burkholder and Pseudomonas syringae pv. phaseolicola Burkholder (Young); iv) the effect of the above treatments on the suppression of fungal disease incidence colonizing the $P$. vulgaris seeds.

\section{Materials and Methods}

\section{Preparation of hydrogel formulations}

The formula of preparation the hydrogel is: $3 \mathrm{~g} / \mathrm{L}$ gelatin, $1 \mathrm{~g} / \mathrm{L}$ polyethylene Glycol (PEG) and $1 \mathrm{~g} / \mathrm{L}$ starch. The mixture was vortexed for 5 minutes, autoclaved at $121^{\circ} \mathrm{C} / 20 \mathrm{~min}$ and left after that for air cooling before adding each single antagonizing microorganism, org EO or OL at $45 \pm 2^{\circ} \mathrm{C}$. The hydrogel formulations are listed in Table 1.

The suggested doses of the tested treatments have been selected according to a previous preliminary analysis using large spectrum of possible concentrations in order to screen the most effective treatments and the possible concentrations could be used effectively in the successive in vitro assays. In fact, the best results have been observed in the case of the following proposed concentrations (1000, 500 and 100 ppm) for org EO and (4000, 2000 and $1000 \mathrm{ppm})$ for OL as specified in Table 1.

\section{Antimicrobial activity of treated hydrogel}

The antimicrobial activity has been carried out for evaluating the in vitro microbicide action of the above mentioned formulations containing hydrogel at three different concentrations and for investigating the antagonistic effect of two microorganisms against some common phytopathogens infecting $P$. vulgaris. The following three antimicrobial assays have been carried out.

\section{Antibacterial assay}

Tested phytopathogenic bacteria: The tested bacteria were $P$. s. pv. phaseolicola, C. michiganensis and X. phaseoli var. fuscans. All bacteria were conserved in the collection of the School of Agricultural, Forestry, Food, and Environmental Sciences (SAFE), University of Basilicata, Potenza, Italy. Recently, C. michiganensis has been reported as possible pathogenic bacteria for $P$. vulgaris causing a newly identified bacterial disease named bacterial bean leaf yellowing. ${ }^{12}$

Disc diffusion method: The antibacterial assay of the tested org EO at (100, 500 and $1000 \mathrm{ppm})$ and ornithine lipid at (1000, 2000 and $4000 \mathrm{ppm}$ ) mixed with hydrogel was investigated following

Table 1. The studied new innovative formulations containing hydrogel used in this study.

\begin{tabular}{lclc} 
& No. & Components of new hydrogel formulations & \\
Bioactive substances & 1 & Hydrogel + Oregano EO $1000 \mathrm{ppm}$ & H.org1000 \\
& 2 & Hydrogel + Oregano EO $500 \mathrm{ppm}$ & H.org500 \\
& 3 & Hydrogel + Oregano EO $100 \mathrm{ppm}$ & H.org100 \\
& 4 & Hydrogel + Ornithine Lipid $4000 \mathrm{ppm}$ & H.OL4000 \\
& 5 & Hydrogel + Ornithine Lipid $2000 \mathrm{ppm}$ & H.OL1000 \\
Antagonists & 6 & Hydrogel + Ornithine Lipid $1000 \mathrm{ppm}$ & H.T22 \\
& 7 & Hydrogel + Trichoderma harzianum T22 $10^{6}$ CFU.ml & H.B.glad \\
\hline Control & 8 & Hydrogel + Burkholderia gladioli $10^{8}$ CFU.m & -1 \\
& 9 & Hydrogel+ positive control (Fungal pathogens) & H.(+ve) cont. \\
\hline
\end{tabular}


the disc diffusion method. ${ }^{13}$ The studied bacterial strains have been cultured on King B nutrient media (KB). The bacterial suspensions were prepared in sterile hydrogel at $10^{6} \mathrm{CFU} / \mathrm{mL}$ doses. Mixtures of bacterial suspensions in soft agar $(0.7 \%)$ were prepared at 9:1; $(v / v)$ and then $4 \mathrm{~mL}$ of this mixture was poured into each Petri dish $(90 \mathrm{~mm})$. Tween $20(0.2 \%)$ was added to EO: hydrogel mixture to enhance its solubility and to avoid the cellular aggregation. Discs (6 mm-OXOID) were placed on the surface of Petri dishes and 15 $\mu \mathrm{L}$ from each tested concentration were added and then all plates were incubated at $30 \pm 2{ }^{\circ} \mathrm{C}$ for $24 \mathrm{hrs}$. The bactericidal effect of the above treatments was evaluated by measuring the diameter of inhibition zone $(\mathrm{mm})$ in comparison to tetracycline antibiotic (1600 $\mu \mathrm{g} . \mathrm{ml}^{-1}$ ). The growth inhibition percentage (GIP) was calculated using the following equation:

$$
\mathrm{GIP}=100-\frac{(\mathrm{GC}-\mathrm{GT})}{\mathrm{GC}} \times 100
$$

Where: GIP represents the bacterial inhibition percentage, GC the average diameter of bacterial grown in plate (control) in $\mathrm{mm}$ and GT the average diameter of inhibition zone in $\mathrm{mm}$. The test was repeated twice with three replicates.

\section{Antifungal assay}

Tested phytopathogenic fungi: Antifungal effect assay was carried out against some common fungal diseases of $P$. vulgaris both seedborne diseases such as $R$. solani, S. sclerotiorum and F. oxysporum and post-harvest pathogenic fungi for bacilli or seeds such as $P$. expansum and A. flavus.

Incorporation methods: The fungicidal activity of the above studied new hydrogel formulations was evaluated following the incorporation methods directly into Potato Dextrose Agar (PDA) medium at $45^{\circ} \mathrm{C} .{ }^{14} \mathrm{~A}$ fresh fungal disk $(\varnothing 0.5 \mathrm{~cm})$ was inoculated in the center of Petri dish. All plates were incubated at $22 \pm 2^{\circ} \mathrm{C}$ for 96 hours under darkness and the diameter of fungal mycelium growth was measured in mm. PDA plates without any treatment were inoculated only with fungal disks as negative control (-ve). The diameter of fungal mycelium growth was measured in $\mathrm{mm}$ and the fungal toxic effect was expressed as percentage of mycelium growth inhibition (PGI \%) compared to (-ve) control using the formula reported by Zygadlo et al.: ${ }^{15}$

$$
\operatorname{PGI}(\%)=\frac{(G C-G T)}{G C} \times 100
$$

Where PGI is the percentage of growth inhibition, GC is the average diameter of fungal mycelium in PDA (Control), and GT is the average diameter of fungal mycelium on the oil-treated PDA dish.

\section{Antagonistic assay}

The antagonistic effect has investigated for B. gladioli and $T$. harzianum T22 incorporated into the prepared hydrogel was evaluated for their antagonistic activity against the above mentioned target phytopathogenic bacteria and fungi. ${ }^{16}$ In particular, single small mass from fresh culture $(24 \mathrm{hrs})$ of B. gladioli and $T$. harzianum T22 were deposited in the centre of Petri dish containing $\mathrm{KB}$ as nutrient media. Successively, suspensions of the tested bacteria and fungi were applied at $10^{8} \mathrm{CFU} \cdot \mathrm{ml}^{-}$and $10^{6} \mathrm{CFU} \cdot \mathrm{ml}^{-1}$, respectively. All plates were incubated at $30^{\circ} \mathrm{C}$ for 24 hours. The antagonistic bacterial effects of the above treatments was evaluated by measuring the diameter of inhibition zone $(\mathrm{mm})$ in comparison to tetracycline antibiotic $\left(1600 \mu \mathrm{g} \cdot \mathrm{ml}^{-1}\right)$ and the Growth Inhibition Percentage (GIP) was calculated using the following equation:

$$
\mathrm{GIP}=100-\frac{(G C-G T)}{G C} \times 100
$$

Where: GIP represents the bacterial inhibition percentage, GC the average diameter of bacterial grown in plate (control) in $\mathrm{mm}$ and GT the average diameter of inhibition zone in $\mathrm{mm}$. The test was repeated twice with three replicates.

The antagonistic fungal effect has been investigated following contact-phase method. ${ }^{4}$ Ten $\mu 1$ of two antagonistic microbial suspensions were deposited on a PDA-Petri dish previously inoculated with a fungal disc $\left(0.5 \mathrm{~cm}^{2}\right)$. All plates were incubated at $22 \pm 2{ }^{\circ} \mathrm{C}$ for 96 hours. The diameter of fungal mycelium growth was measured in mm. Fungal toxic effect was expressed as percentage of mycelium growth inhibition (PGI \%) compared to (-ve) control using the formula reported by Zygadlo et al.: ${ }^{15}$

$$
\text { PGI }(\%)=\frac{(G C-G T)}{G C} \times 100
$$

Where PGI is the percentage of growth inhibition, GC is the average diameter of fungal mycelium in PDA (Control), and GT is the average diameter of fungal mycelium on the oil-treated PDA dish.

\section{Seed germination assay}

The experiment seed germination assay was carried out for evaluation the effect of hydrogel formulations incorporated with the highest tested doses of the above mentioned bioactive substances or antagonistic microorganisms as following: i) H.org1000; ii) H.OL4000; iii) H.T22; iv) H.B.glad ; v) control (H2O); vi) H.(-ve) control on the germinability of $P$. vulgaris seeds of Ciuoto landrace, protected by the European Union with Fagioli di Sarconi PGI (Protected Geographical Indication) mark, and cultivated in Basilicata area (Southern Italy).

The above mentioned concentrations have been selected based on the highest doses of both tested substances org EO and OL in order to investigate their eventual negative collateral effect against the germinability of $P$. vulgaris seeds.

The methodological procedures have been performed by application the above mentioned formulations on the studied seeds, then were vortexed and remain under laminar flow for $30 \mathrm{~min}$. The seeds have been dried after that on filter paper for 24 hours at room temperature. Successively, the seeds were placed in glass Petri dishes (20 cm diameter) pre-filled with small layer of agar (1\%) of $2 \mathrm{~mm}$ thickness and incubated in growth chamber at $22^{\circ} \mathrm{C} / 12$ hours photoperiod for 7 days. A completely randomized block design with three replications was three replicates have been considered for each treatment and 20 seeds per each replicate.

The effect of hydrogel on the seed germinability has been evaluated by counting the number of germinated seeds in each treatment compared to control. Seeds with $2 \mathrm{~mm}$ of radical elongation were considered as germinated as explained by Pazderů. ${ }^{17}$ The Seed Germination Index (SGI) has been calculated using the following equation:

$$
S G I=\frac{\text { N.S.Gt }}{\text { N.S.GC }} X 100
$$

Where: SGI = seed germination index; S.Gt: seed germination in each prepared hydrogel formulation; S.Gc: seed germination in control $\mathrm{H}_{2} \mathrm{O}$.

The Mean of Germination Period (MGP) has been examined by counting the minimum necessary days for achieving the $50 \%$ germinations of the tested seeds. The effect of studied hydrogel formulations on the percent of seed germination has been also cal- 
culated in relation to the whole incubation period in growth chamber as reported by Pazderů. ${ }^{17}$

\section{Suppression of disease incidence on $\boldsymbol{P}$. vulgaris seeds}

The test of suppression of disease incidence has been carried out against some common fungal pathogens of $P$. vulgaris. The obtained results of the previous antagonistic activity of both Trichoderma and Burkholderia confirmed their antagonistic effect against the tested fungal pathogens. Whereas as there is no sufficient bibliographic research of using OL and org EO against the same fungal pathogens, hence the current assay has been performed to study the effect of new prepared hydrogel formulation based OL and org EO against the disease incidence on $P$. vulgaris seeds.

All tested seeds have been sterilized using sodium hypochlorite $(5 \%)$ solution for 4-5 minutes then washed by distilled sterile water 2-3 times and then were dried on filter paper for 30 minutes. The seeds were emerged inside the new formulations and were then vortexed for 5 minutes then remain under laminar flow over night at room temperature $\left(22^{\circ} \mathrm{C}\right)$. Successively, the seeds were emerged in fungal suspension $\left(10^{6} \mathrm{CFU} \cdot \mathrm{ml}^{-1}\right)$ of each tested fungi: F. oxysporum, R. solani, S. sclerotiorum, P. expansum and A. flavus for 10 minutes then were placed in Petri dishes $(90 \mathrm{~mm}$ diameter) pre-filled with $14 \mathrm{ml}$ PDA and incubated in growth chamber at $22 \pm 2{ }^{\circ} \mathrm{C}$ for 96 hours. For the positive control, 10 untreated seeds have been sterilized and inoculated separately with each fungal suspension. Three replicates have been considered for each treatment and 20 seeds per each replicate. The effect of new prepared hydrogel formulations on disease incidence has been evaluated by measuring the percentage of fungal colonization of each seed.

\section{Statistical analysis}

The obtained results from biofilm and antagonistic assays were statistically processed using Statistical Package for the Social Sciences (SPSS) version 13.0 (Prentice Hall: Chicago, USA, 2004). The analysis of variance one-way ANOVA and Duncan Post
Hoc multiple comparison tests have been performed with a probability of $\mathrm{P}<0.05$.

\section{Results}

\section{Antimicrobial activity of treated hydrogel}

\section{Antibacterial assay}

The results of bactericidal effect of the studied hydrogel formulations based bioactive substances showed that, H.org1000 formulation has the highest significant antibacterial activity against all tested bacteria except $X$. phaseoli var. fuscans where it showed moderate activity lower than tetracycline (Table 2). In particular, H.org500 and H.OL4000 showed moderate activity against $C$. michiganensis and X. phaseoli var. fuscans. In addition, there is no significant difference between the antibacterial effect attributed to H.org1000 and H.org500 against P. s. pv. phaseolicola (Table 2). The lowest significant activity against all tested bacteria has been observed in the case of H.OL1000 (Table 2).

\section{Fungicidal assay}

The fungicidal results of the studied hydrogel formulations based bioactive substances, showed that the H.org1000 formulation has the highest significant antifungal activity against $F$. oxysporum, $R$. solani, $P$. expansum and $A$. flavus, with a prohibition of growth rate percentage equal to $68,59,63$ and $53 \%$, respectively (Table 3). Whereas, H.OL4000 formulation has the highest significant antifungal activity against $S$. sclerotiorum, $P$. expansum and A. flavus equal to 83,62 and $63 \%$, respectively (Table 3 ). In addition, H.org500 and H.OL4000 showed moderate activity against $F$. oxysporum and $R$. solani (Table 3 ). On the other hand, H.org100 formulation demonstrated the lowest significant antifungal activity against all tested fungi (Table 3).

Table 2. Bactericidal effect of hydrogel formulations based bioactive substances.

\begin{tabular}{|c|c|c|c|c|c|c|c|}
\hline \multirow{3}{*}{ Bacteria } & \multicolumn{6}{|c|}{ Bacterial Growth Inhibition (\%) } & \multirow{3}{*}{$\begin{array}{l}\text { Tetracyclin } \\
1600 \mu \mathrm{g} / \mathrm{ml}\end{array}$} \\
\hline & \multirow{2}{*}{\multicolumn{3}{|c|}{$\begin{array}{l}\text { Oregano EO (ppm) } \\
\end{array}$}} & \multicolumn{3}{|c|}{ Ornithine Lipid (ppm) } & \\
\hline & H.org1000 & & H.org 100 & H.OLA000 & H.OL2000 & H.OL1000 & \\
\hline C. michiganensis & $80,0 \pm 2,6 \mathrm{a}$ & $60,0 \pm 4,1 a b$ & $28,9 \pm 2,6 \mathrm{~b}$ & $55,6 \pm 5,7 \mathrm{ab}$ & $27,8 \pm 4,3 b$ & $5,6 \pm 0,6 \mathrm{c}$ & $62,2 \pm 3,1 a b$ \\
\hline X.phaseoli & $62,2 \pm 2,6 \mathrm{~b}$ & $52,2 \pm 5,0 \mathrm{~b}$ & $25,6 \pm 3,8 \mathrm{bc}$ & $30,0 \pm 4,7 \mathrm{bc}$ & $15,6 \pm 2,1 \mathrm{c}$ & $0,0 \pm 0,0 \mathrm{~d}$ & $90,0 \pm 2,2 \mathrm{a}$ \\
\hline P. s. pv. phaseolicola & $70,0 \pm 3,8 \mathrm{a}$ & $62,2 \pm 2,6 \mathrm{a}$ & $32,2 \pm 1,3 \mathrm{ab}$ & $48,9 \pm 5,1 \mathrm{ab}$ & $37,8 \pm 5,1 \mathrm{ab}$ & $18,9 \pm 0,4 \mathrm{~b}$ & $60,0 \pm 4,4 \mathrm{a}$ \\
\hline
\end{tabular}

Values are recorded as the mean of bacterial growth inhibition percentage. Values followed by the different letter in each horizontal row for each tested bacteria are significantly different according to Duncan test at $\mathrm{P}<0.05$. Data were obtained from three replicates \pm SDs.

Table 3. Fungicidal effect of hydrogel formulations based bioactive substances.

\begin{tabular}{|c|c|c|c|c|c|c|c|c|}
\hline \multirow{3}{*}{ Fungi } & \multicolumn{6}{|c|}{ Fungal growth inhibition (\%) } & \multirow{3}{*}{\multicolumn{2}{|c|}{$\begin{array}{c}\text { Control } \\
\text { H. (-ve) cont H.(+ve) cont. }\end{array}$}} \\
\hline & \multicolumn{3}{|c|}{ Oregano EO (ppm) } & \multicolumn{3}{|c|}{ Ornithine Lipid (ppm) } & & \\
\hline & H.org1000 & H.org500 & H.org 100 & H.OLA000 & H.0L2000 & H.0L1000 & & \\
\hline F. oxysporum & $68,2 \pm 2,1 \mathrm{a}$ & $31,6 \pm 1,8 b$ & $7,1 \pm 1,1 \mathrm{c}$ & $34,0 \pm 1,2 b$ & $19,0 \pm 1,2 b c$ & $7,0 \pm 1,2 \mathrm{c}$ & $6,0 \pm 1,2 \mathrm{c}$ & $0,0 \pm 0,0 \mathrm{~d}$ \\
\hline R. solani & $59,0 \pm 1,2 \mathrm{a}$ & $29,5 \pm 0,6 \mathrm{~b}$ & $5,2 \pm 0,5 \mathrm{c}$ & $23,5 \pm 1,7 \mathrm{~b}$ & $20,0 \pm 2,3 b$ & $5,0 \pm 1,2 \mathrm{c}$ & $7,0 \pm 1,2 \mathrm{c}$ & $0,0 \pm 0,0 \mathrm{~d}$ \\
\hline S. sclerotiorum & $45,5 \pm 6,4 \mathrm{~b}$ & $26,0 \pm 1,2 \mathrm{c}$ & $9,5 \pm 0,6 \mathrm{~d}$ & $82,6 \pm 3,0 \mathrm{a}$ & $47,8 \pm 3,2 b$ & $25,3 \pm 3,8 \mathrm{c}$ & $3,0 \pm 1,2 \mathrm{~d}$ & $0,0 \pm 0,0 \mathrm{e}$ \\
\hline P. expansum & $62,6 \pm 1,8 \mathrm{a}$ & $26,2 \pm 4,4 \mathrm{~b}$ & $4,0 \pm 0,6 c$ & $62,1 \pm 3,3 \mathrm{a}$ & $37,8 \pm 3,8 \mathrm{~b}$ & $27,6 \pm 8,5 b$ & $8,0 \pm 2,3 \mathrm{c}$ & $0,0 \pm 0,0 \mathrm{~d}$ \\
\hline A. flavus & $53,5 \pm 2,8 \mathrm{a}$ & $5,3 \pm 0,8 \mathrm{c}$ & $2,0 \pm 0,6 \mathrm{c}$ & $62,7 \pm 2,0 \mathrm{a}$ & $33,5 \pm 2,9 \mathrm{~b}$ & $16,0 \pm 2,3 \mathrm{bc}$ & $8,0 \pm 1,2 \mathrm{c}$ & $0,0 \pm 0,0 \mathrm{~d}$ \\
\hline
\end{tabular}

Values are recorded as the mean of fungal growth inhibition percentage. Values followed by the different letter in each horizontal row for each tested fungi are significantly different according to Duncan test at $\mathrm{P}<0.05$. Data were obtained from three replicates \pm SDs. 


\section{Antagonistic assay}

The antagonistic bacterial activity, results showed that H.T22 (cells) formulation has the highest significant antibacterial activity against $C$. michiganensis and $P$. s. pv. phaseolicola compared to tetracycline. Whereas, H.T22 (filtrate) formulation has the highest antibacterial effect against $C$. michiganensis and $X$. phaseoli var. fuscans (Table 4).

Regarding the antagonistic fungal activity, results showed that H.B.glad (filtrate) formulation has the highest significant antifungal activity against all tested fungi. In addition, H.T22 (cells) showed the highest significant activity against $R$. solani, $S$. sclerotiorum and P. expansum whereas that H.B.glad (cells) formulation showed the highest significant activity against $A$. flavus (Table 5).

\section{Seed germinability assay}

The obtained results of the effect of hydrogel on the seed germination of $P$. vulgaris (in vitro) demonstrated that seeds treated with hydrogel did not show influence on number of seeds germinated (Figure 1). In particular, results showed also that the highest significant seed germination percentage has been achieved in the case of hydrogel formulation with B. gladioli (H.B.glad) and $\mathrm{H}_{2} \mathrm{O}$, then H.(ve) cont. and H.org1000. However, hydrogel formulation with $T$. harzianum (H.T22) and ornithine lipid (H.OL) showed moderate seed germination percentage as demonstrated in Figure 1.
After 7 days in Petri dishes, seeds of $P$. vulgaris germinated most rapidly in the case of H.B.glad treatment where it demonstrated the highest significant germination percentage 100\% (Table 6). In addition, the germination percentage increased gradually in all tested treatments until the seventh day of incubation, whereas, the lowest germination percentage has been observed in the case of H.OL4000 and H.T22 after the seventh day of incubation (Table $6)$. On the other hand, the seed germination rate in the case of H.org1000 was significantly higher than H.(-ve) cont, where the percentage was gradually increased from 23 to $90 \%$ compared to 14 to $89 \%$ from the first to the seventh day of incubation (Table 6).

\section{Suppression of disease incidence on $P$. vulgaris seeds}

Results of the disease incidence of the tested phytopathogenic fungi showed that H.org and H.OL formulations were able to suppress significantly the disease of all tested fungi on the $P$. vulgaris seeds in a dose dependent manner (Figure 2). In particular, H.org 1000 and H.OL4000 formulations explicated the highest significant disease suppression against $F$. oxysporum, $S$. sclerotiorum and $A$. flavus (Figure 2). Regarding $R$. solani, the highest growth inhibition has been observed in the case of H.org 1000 followed by H.org500 and H.OL4000 where the latter have explicated a moderate activity (Figure 2). Whereas, H.OL4000 showed the highest significant disease suppression against $P$. expansum followed by

Table 4. Antagonistic bacterial activity of B. gladioli and T. harzianum T22 in hydrogel formulation.

\begin{tabular}{lccccc} 
Bacteria & \multicolumn{3}{c}{ Bacterial growth inhibition (\%) } & & \\
& Cells & F.B.glad & H.T22 & Tetracyclin \\
C. michiganensis & $31,0 \pm 0,2 \mathrm{c}$ & $52,2 \pm 0,4 \mathrm{~b}$ & $84,4 \pm 0,1 \mathrm{a}$ & $80,0 \pm 0,3 \mathrm{a}$ & $62,2 \pm 3,1 \mathrm{ab}$ \\
$X$. phaseoli & $13,3 \pm 0,1 \mathrm{c}$ & $43,3 \pm 0,1 \mathrm{~b}$ & $51,1 \pm 0,2 \mathrm{~b}$ & $82,0 \pm 0,3 \mathrm{a}$ & $90,0 \pm 2,2 \mathrm{a}$ \\
\hline P. s. pv. phaseolicola & $37,8 \pm 0,3 \mathrm{c}$ & $56,7 \pm 0,5 \mathrm{~b}$ & $85,6 \pm 0,2 \mathrm{a}$ & $63,0 \pm 0,4 \mathrm{~b}$ & $60,0 \pm 4,4 \mathrm{~b}$ \\
\hline
\end{tabular}

Values followed by different letters within each row are significantly different according to Duncan test at $\mathrm{P}<0.05$. All values are presented as mean of 3 replicates \pm SDs.

Table 5. Antagonistic fungal activity of B. gladioli and T. harzianum T22 in hydrogel formulation.

\begin{tabular}{|c|c|c|c|c|c|c|}
\hline \multirow[t]{2}{*}{ Fungi } & \multicolumn{6}{|c|}{ Fungal growth inhibition (\%) } \\
\hline & Cells & Filtrate & Cells & Filtrate & H.(-ve) cont & H.(+ve) cont. \\
\hline F. oxysporum & $30,0 \pm 3,0 \mathrm{~b}$ & $52,2 \pm 3,8 \mathrm{a}$ & $13,3 \pm 2,6 \mathrm{~b}$ & $22,2 \pm 2,6 b$ & $6,0 \pm 1,2 \mathrm{bc}$ & $0,0 \pm 0,0 \mathrm{c}$ \\
\hline R. solani & $17,8 \pm 2,0 \mathrm{ab}$ & $33,3 \pm 5,1 \mathrm{a}$ & $20,0 \pm 2,6 \mathrm{a}$ & $10,0 \pm 1,3 \mathrm{ab}$ & $7,0 \pm 1,2 \mathrm{~b}$ & $0,0 \pm 0,0 \mathrm{c}$ \\
\hline S. sclerotiorum & $16,7 \pm 3,0 \mathrm{ab}$ & $22,2 \pm 2,6 \mathrm{a}$ & $30,0 \pm 3,8 \mathrm{a}$ & $11,1 \pm 2,6 \mathrm{ab}$ & $3,0 \pm 1,2 \mathrm{~b}$ & $0,0 \pm 0,0 \mathrm{c}$ \\
\hline P. expansum & $14,4 \pm 3,0 a b$ & $31,1 \pm 5,1 a$ & $23,3 \pm 3,8 a$ & $14,4 \pm 1,3 a b$ & $8,0 \pm 2,3 b$ & $0,0 \pm 0,0 c$ \\
\hline A. flavus & $36,7 \pm 3,0 \mathrm{a}$ & $43,3 \pm 3,8 \mathrm{a}$ & $0,0 \pm 0,0 \mathrm{c}$ & $51,1 \pm 5,1 \mathrm{a}$ & $8,0 \pm 1,2 \mathrm{~b}$ & $0,0 \pm 0,0 \mathrm{c}$ \\
\hline
\end{tabular}

Values followed by different letters within each row are significantly different according to Duncan test at $\mathrm{P}<0.05$. All values are presented as mean of 3 replicates \pm SDs .

Table 6. Effect of hydrogel formulations on percent germination of P. vulgaris.

\begin{tabular}{|c|c|c|c|c|}
\hline Treatments & & Days A & eeding & \\
\hline & $1^{\text {st }}$ & $3^{\text {rd }}$ & $5^{\text {th }}$ & $7^{\text {th }}$ \\
\hline $\mathrm{H}_{2} \mathrm{O}$ & $25,0 \pm 4,4 \mathrm{a}$ & $38,0 \pm 5,1 \mathrm{a}$ & $76,7 \pm 5,3 \mathrm{~b}$ & $95,0 \pm 5,8 \mathrm{a}$ \\
\hline H.(-ve) cont. & $14,0 \pm 4,7 \mathrm{~b}$ & $26,0 \pm 5,5 \mathrm{~b}$ & $65,7 \pm 4,5 b$ & $89,0 \pm 3,4 \mathrm{ab}$ \\
\hline H.B.glad & $27,0 \pm 5,7 \mathrm{a}$ & $42,0 \pm 3,1 \mathrm{a}$ & $90,0 \pm 5,4 \mathrm{a}$ & $100,0 \pm 2,3 \mathrm{a}$ \\
\hline H.T22 & $13,0 \pm 4,0 \mathrm{~b}$ & $20,5 \pm 4,3 \mathrm{bc}$ & $66,7 \pm 5,8 \mathrm{~b}$ & $85,0 \pm 5,7 \mathrm{~b}$ \\
\hline H.org1000 & $23,0 \pm 6,7 \mathrm{a}$ & $32,0 \pm 6,3 \mathrm{~b}$ & $73,3 \pm 5,1 \mathrm{~b}$ & $90,0 \pm 2,2 \mathrm{ab}$ \\
\hline H.OL4000 & $11,0 \pm 3,0 \mathrm{~b}$ & $19,5 \pm 4,4 \mathrm{bc}$ & $65,4 \pm 7,9 \mathrm{~b}$ & $80,0 \pm 7,7 \mathrm{~b}$ \\
\hline
\end{tabular}

Values followed by different letters within each columns are significantly different at $\mathrm{P}<0.05$ according to Duncan post hoc test. All values are presented as mean of 3 replicates \pm SDs. 
H.org 1000 (Figure 2). In most of cases, H.org treatments at all tested doses were significantly active higher than H.OL treatments.

\section{Discussion}

The high number of germinated seeds and the higher germination percentage in the case of hydrogel treatment could be correlated to the gel layer of seed covering which may help in retaining and maintaining the moisture throughout the germination phase. ${ }^{18}$ In addition, these formulations containing $B$. gladioli and org EO may also enhance the metabolic activity of seeds and increase their germinability process. There is no higher significant differences of seed germination percentage in relation to the two tested formulations H.org1000 and H.OL4000 (90 and 80\%), respectively compared to the negative control $\mathrm{H}_{2} \mathrm{O}(95 \%)$. These obtained results, especially with the use of the highest concentrations of the two aforementioned treatments (Org EO and OL), are considered a clear indication that there are no collateral effects of using the new innovative formulations based hydrogel.

The obtained results showed that the hydrogel formulation containing B. gladioli has the highest significant in vitro antimicrobial effect against the majority of tested phytopathogens. This effective antimicrobial activity is in agreement with different studies reported that many Burkholderia species have the ability to control effectively many fungal diseases and can also promote plant growth. ${ }^{4}$ Some Burkholderia species have been already registered as biocontrol agents for many plant-pathogenic fungi by the U.S. environmental protection agency, such as Pythium aphanidermatum, F. oxysporum, Botrytis cinerea and R. solani. ${ }^{19}$

The antimicrobial activity of $B$. gladioli could be due to their high ability to produce extracellular hydrolytic enzymes such as chitinase, protease, cellulase, amylase and glucanase which play an important role in destroying the cell walls of many pathogenic fungi and hence inhibiting their growth. ${ }^{19,20}$ The production of some Volatile Organic Compounds (VOCs) by B. gladioli could play an essential role in the inhibition of fungal pathogens as reported by Elshafie et al. ${ }^{4}$ who concluded that strains of $B . g$. pv. agaricicola produced bioactive VOCs able to reduce the mycelium growth of $F$. oxysporum and $R$. solani.

The antifungal activity of $B$. gladioli against some serious phytopathogenic fungi such as A. flavus, $P$. expansum, $S$. sclerotiorum, $F$. oxysporum and $R$. solani, at the same amount of bacterial suspension used in the current study $\left(10^{8} \text { CFU.mL }{ }^{-1}\right)^{4}$ has been confirmed in previous bibliographic research. These previously mentioned results are a real indication that the antimicrobial activity of $B$. gladioli has not been altered by its involvement in the new studied hydrogel formulations and it can also be emphasized that the hydrogel did not interfere with the biological activity of the tested bacterium.

In addition, the biological effect of OL containing hydrogel observed in the current study is in accordance with the results obtained by Tahara et al. ${ }^{21}$ who reported that OL has a large spectrum antimicrobial effect against many gram negative (G-ve) and gram positive $(\mathrm{G}+\mathrm{ve})$ phytopathogenic bacteria and variety of yeasts and fungi such as Candida albicans, Cryptococcus neoformas, Saccharomyces cerevisiae and Aspergillus niger.

Likewise, Elshafie et al. ${ }^{22}$ reported that OL is characterized by a broad spectrum of antimicrobial effects against some pathogenic bacteria such as Alcaligenes faecalis, Bacillus subtilis, Escherichia coli and Pseudomonas aeruginosa. While the latter explained that the cell free culture filtrate of $B . g$. pv. agaricicola has antibacterial activity against $B$. megaterium and $E$. coli and the chemical identification of this filtrate explained that the main single compound was OL. ${ }^{12}$ Accordingly, the mechanism of action of OL or Hydroxy-OLs to stimulate the vegetative growth and increase its resistance to microbial diseases might extend to their involvement in acid tolerance, decrease membrane permeability because of increased hydrogen bonding between different hydroxyl-OL molecules and later on by helping plant cells for nitrogen fixation., ${ }^{7,23}$ On the other hand, Hussein et al..$^{23}$ reported that the application of L-ornithine in sugar beet plants has improved their drought tolerance.

Furthermore, OLs compounds are considered important regulators for the biosynthesis and accumulation of glutamine in the cells, and can play a role in the optimal carbon and nitrogen assimilation which in turn leads to increase the biomass production and abiotic stress tolerance in plants. ${ }^{23}$ Therefore, the use of OL in field experiments could has an interesting effect on the physiological parameters of the plant in agreement with Hussein et al. ${ }^{23}$ who concluded that the foliar application of L-ornithine, especially at low concentrations, was able to improve some plant growth parameters especially for stressed plants. On the other hand, Çavuşoğlu and Çavuşoğlu ${ }^{24}$ observed that seed germination and seedling growth were significantly decreased with the application of L-ornithine, however, there was a positive role in reducing salt damage.

Regarding the biological activity of the hydrogel formulation containing T. harzianum T22, there are a number of studies reported the effective antagonistic effect of T22 as well as its principal bioactive secondary metabolites such as T22-azaphilone, harzianolide and T39-butenolide against $R$. solani and P. ultimum. ${ }^{25}$ Furthermore, some of cell wall degrading enzymes isolated from Trichoderma sp. showed a promising fungicidal effect against $F$. oxysporum. ${ }^{25}$

The biological efficacy of some Trichoderma isolates has been

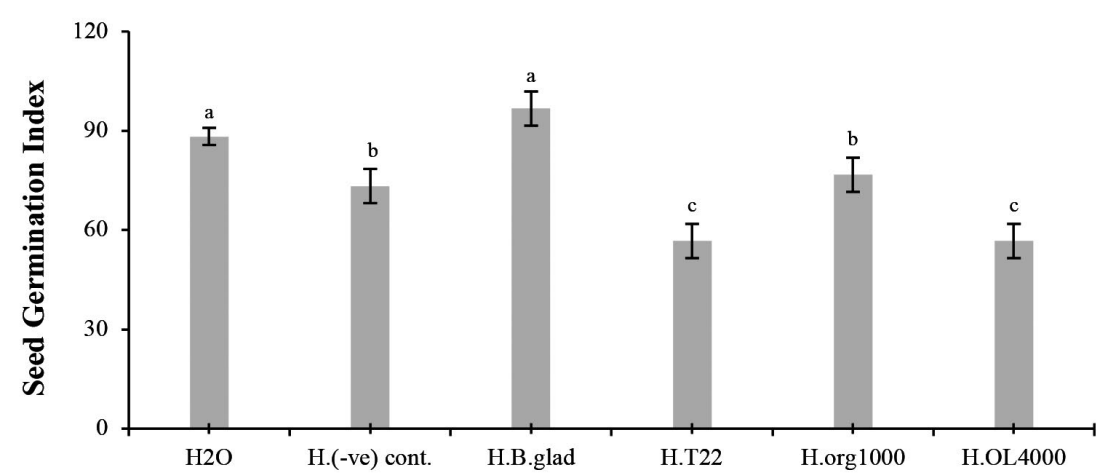

Figure 1. Performance of new hydrogel formulations on seed germination index of $P$. vulgaris $\mathrm{L}$. Bars with different letters indicate means values significantly different at $\mathbf{P}<\mathbf{0 . 0 5}$ according to Duncan post hoc test. Data are expressed as the mean of three replicates \pm SDs. Where: $H$.(-ve) cont.$=$ only Hydrogel; H.B.glad = Hydrogel + Burkbolderia gladioli at $10^{8}$ CFU.ml ${ }^{-1}$; H.T22 = Hydrogel + Trichoderma harzianum T22 at $10^{6}$ CFU.ml ${ }^{-1}$; H.org1000 $=$ hydrogel + oregano $\mathrm{EO}$ at 1000 ppm; H.OL4000 = Hydrogel + Ornithine Lipid at 4000 ppm. 
documented against some serious phytopathogenic fungi. In particular, Chao and Wen-Ying ${ }^{26}$ studied the biocontrol of some Trichoderma isolates against $R$. solani causing root rot of Vigna unguiculata and concluded that some of the studied isolates were able to reduce the disease severity incidences of $R$. solani and promote plant growth. In addition, the same authors have attributed the growth promoting effect of some Trichoderma isolates to their production of indole acetic acid and siderophores from one side and also to their ability of phosphate solubilization from another side. ${ }^{26}$ Zhang et al. ${ }^{27}$ studied the biocontrol effect of T. harzianum against $S$. sclerotiorum in soybean and concluded that it was able to significantly biocontrol $S$. sclerotiorum due to two different pathways: i) direct mechanism such as hyphal parasitism and secretion antifungal metabolites; ii) indirect mechanism by inducing systemic resistance. The same authors also reported also that Trichoderma is considered one important fungal biocontrol agent due to its potential mycoparasitic effect against a wide range of fungal pathogens such as $B$. cinerea, Fusarium spp., Pythium spp., $R$. solani, Sclerotium rolfsii and $S$. sclerotiorum. ${ }^{27}$ The current obtained results will encourage the use of the new hydrogel formulation based Trichoderma and Burkholderia in field trials to also evaluate their antifungal effect against some common diseases of $P$. vulgaris.
Referring to the antimicrobial effect of org EO, various studies reported the antifungal effect against Fusarium moniliforme, $R$. solani, S. sclerotiorum and Phytophthora capisci. ${ }^{14}$ The obtained results of the potential efficacy of tested org EO incorporated into hydrogel formulation could be due to its rich content of phenolic compounds especially carvacrol and thymol in agreement with several studies. ${ }^{14}$ It is also worth noting here that the synergic effect of thymol and carvacrol, the two principals of org EO, showed a trigger in antibiotic susceptibility of many drug resistant bacteria such as Salmonella typhimurium spp., Streptococcus pyogenes and $S$. aureus as reported by Palaniappan and Holley. ${ }^{28}$

The obtained results from the current research are largely consistent with the results observed from Khaledi et al. ${ }^{29}$ who determined that some plant EOs under family Lamiaceae have explicated strong antifungal activity against the two main phytopathogens of bean ( $R$. solani and Macrophomina phaseolina). The same authors discussed the possible mechanism of the fungicidal effect of the studied EOs and stated that they were able to decrease the activity of cell wall degrading enzymes of fungal phytopathogens. In addition, they reported that some single constituents such as menthol showed a remarkable ability in decreasing diseases on bean. ${ }^{29}$

The promising antimicrobial effect of org EO could be due to its
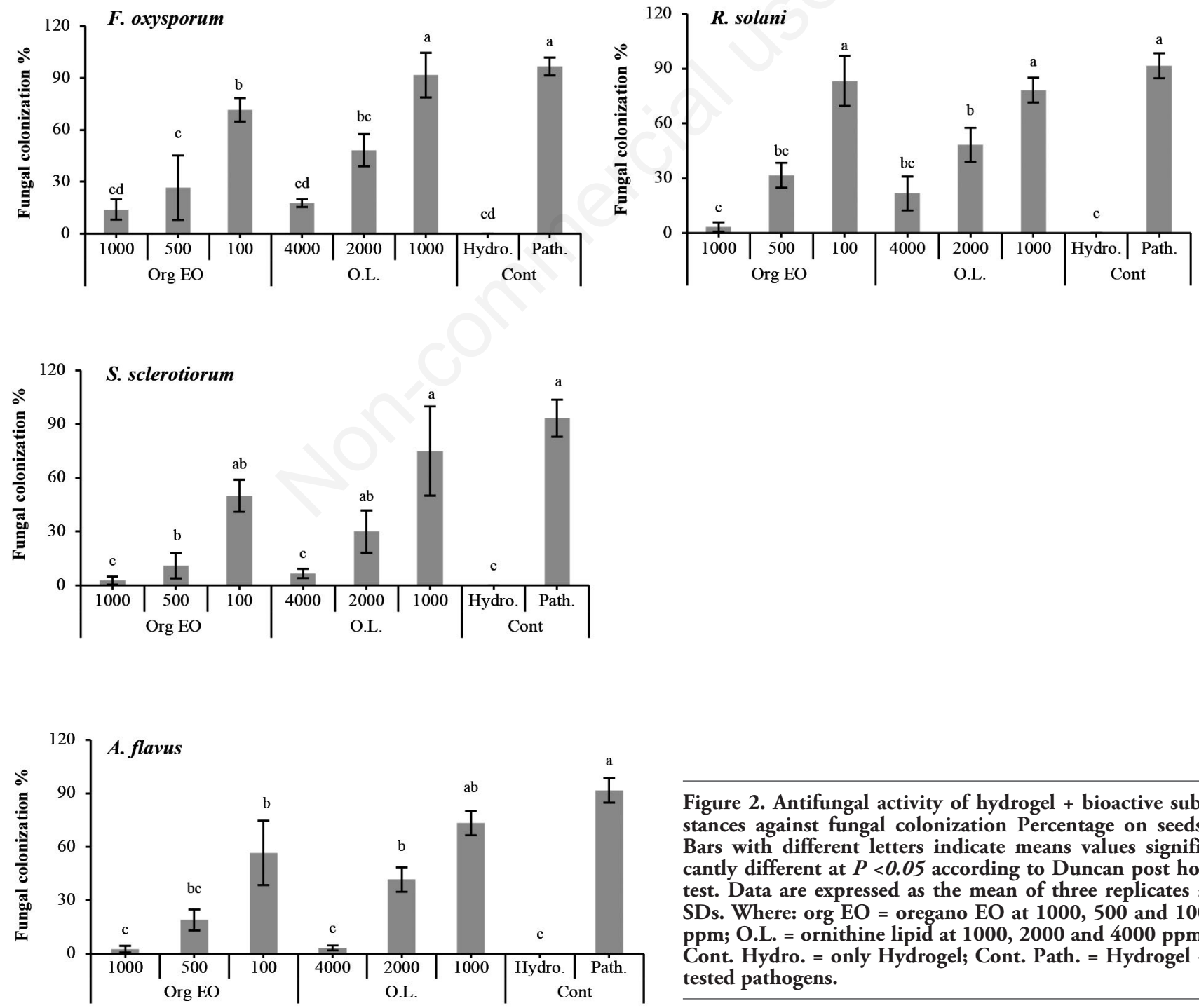

Figure 2. Antifungal activity of hydrogel + bioactive substances against fungal colonization Percentage on seeds. Bars with different letters indicate means values significantly different at $P<0.05$ according to Duncan post hoc test. Data are expressed as the mean of three replicates \pm SDs. Where: org EO = oregano EO at 1000, 500 and 100 ppm; O.L. = ornithine lipid at 1000, 2000 and 4000 ppm; Cont. Hydro. = only Hydrogel; Cont. Path. = Hydrogel + tested pathogens. 
ability to increase the cell membrane permeability and enhance the loss of ions, leakage of macromolecules and lysis. ${ }^{30}$ The lipophilic nature of plant EOs enables them to interfere with cytoplasmic membrane and increase cell permeability and hence cause cell death. ${ }^{10}$ In most cases, the apparent biological efficacy of many plant EOs is mainly due to their major components of i) terpene hydrocarbons such as monoterpenes and sesquiterpenes and ii) oxygenated compounds such as alcohols, phenols, aldehydes and esters. ${ }^{11}$

On the other hand, the positive effect of org EO on seed germination of $P$. vulgaris has been reported also in some bibliographic research where many plant EOs showed biological effect on plant seed germination and development. The observed antifungal activity of org EO against disease suppression of the artificially infected seeds are somewhat consistent with the results of Khaledi et al. ${ }^{29}$ who reported that the seed treatment with peppermint EO and/or menthol significantly reduced the development of bean diseases caused by $R$. solani and M. phaseolina.

\section{Conclusions}

The obtained results indicated the effective antimicrobial activity of the studied innovative hydrogel formulations against some common diseases of $P$. vulgaris. In the same context, the current out-findings encourage the high possibility of using these new formulations on a large scale in seed coating technology. Furthermore, these new bioactive formulations could enhance the systematic resistance against different microbial diseases without the use of chemical and synthetic drugs. Hence, the outcomes from the current study will help in decreasing environmental pollution and its negative impact on plant, animal and human health.

\section{References}

1. Lafon-Placette C, Köhler C. Embryo and endosperm, partners in seed development Author links open overlay panel. Curr Opin Plant Biol 2014;17:64-9.

2. Ehsanfar S, Modarres-Sanavy SAM. Crop protection by seed coating. Commun Agric Appl Biol Sci 2005;70:225-9.

3. Elshafie HS, Racioppi R, Bufo SA, Camele I. In vitro study of biological activity of four strains of Burkholderia gladioli pv. agaricicola and identification of their bioactive metabolites using GC-MS. Saudia J Biol Sci 2017;24:295-301.

4. Elshafie HS, Camele I, Racioppi R, et al. In vitro antifungal activity of Burkholderia gladioli pv. agaricicola against some phytopathogenic fungi. Int J Mol Sci 2012;13:16291-302.

5. Elshafie HS, Devescovi G, Venturi V, et al. Study of the regulatory role of N-Acyl homoserine lactones mediated quorum sensing in the biological activity of Burkholderia gladioli pv. agaricicola causing soft rot of Agaricus spp. Front Microbiol 2019;10:2695.

6. Escobedo-Hinojosa WI, Vences-Guzmán MA, Schubotz F, et al. OlsG (Sinac_1600) is an ornithine lipid N-methyltransferase from the planctomycete Singulisphaera acidiphila. J Biol Chem 2015;290:15102-11.

7. Siebers M, Brands M, Wewer V, et al. Lipids in plant-microbe interactions. Biochim Biophys Acta 2016;1861:1379-95

8. Vinale F, Nigro M, Sivasithamparam K, et al. Harzianic acid: a novel siderophore from Trichoderma harzianum. FEMS Microbiol Lett 2013;347:123-9.
9. Elshafie HS, Mancini E, Camele I, et al. In vivo antifungal activity of two essential oils from Mediterranean plants against postharvest brown rot disease of peach fruit. Indus Crops Produc 2015;66:11-15.

10. Camele I, Elshafie HS, De Feo V, Caputo L. Anti-quorum sensing and antimicrobial effect of Mediterranean plant essential oils against phytopathogenic bacteria. Front Microbiol 2019;10:2619.

11. Raveau R, Fontaine J, Sahraoui AL. Essential oils as potential alternative biocontrol products against plant pathogens and weeds: A Review. Foods 2020;9:1-31.

12. González AJ, Trapiello E. Clavibacter michiganensis subsp. Phaseoli subsp. Nov., Pathogenic in Bean. Int Syst Evol Microbiol 2014;64:1752-5.

13. Elshafie HS, Grul'ová D, Baranová B, et al. Antimicrobial activity and chemical composition of essential oil extracted from Solidago canadensis L. growing wild in Slovakia. Molecules 2019;24:1206.

14. Elshafie HS, Mancini E, Sakr S, et al. Antifungal activity of some constituents of Origanum vulgare L. essential oil against postharvest disease of peach fruit. J Med Food 2015;18:929-34.

15. Zygadlo JA, Guzmán CA, Grosso NR. Antifungal properties of the leaf oils of Tagetes minuta L. and T. filifolia Lag. J Essent Oil Res 1994;6:617-21.

16. Lavermicocca P, Iacobellis N S, Simmaco M, Graniti A. Biological properties and spectrum of activity of Pseudomonas syringae pv. syringae toxins. Physiol Mol Plant Pathol 1997;50:129-40.

17. Pazderů K. Importance of germination energy for seed quality evaluation. In: Proceedings of conference seed and seedlings IX, Praha: ČZU v Praze, 2009;56-60.

18. Gokavi N, Rudragouda MK, Mukharib DS, et al. Performance of hydrogel on seed germination and growth of young coffee seedlings in nursery. J Pharmacogn Phytochem 2018;7:1364-6.

19. Scuderi G, Bonaccorsi A, Panebianco S, et al. Some strains of Burkholderia gladioli are potential candidates for postharvest biocontrol of fungal rots in citrus and apple fruits. J Plant Pathol 2009;91:207-13.

20. Saligkarias ID, Gravanis FT, Harry AS. Biological control of Botrytis cinerea on tomato plants by the use of epiphytic yeasts Candida guilliermondii strains 101 and US 7 and Candida oleophila strain I-182: II. A study on mode of action. Biol Control 2002;25:151-61.

21. Tahara Y, Yamada U, Kond K. Antimicrobial activity of the ornithine-containing lipid isolated from gluconobacter cerinus. Agric Biol Chem 1977;41:417-8.

22. Elshafie HS, Viggiani L, Mostafa MS, et al. Biological activity and chemical identification of ornithine lipid produced by Burkholderia gladioli pv. agaricicola ICMP 11096 using LCMS and NMR analyses. J Biol Res 2017;90:96-103.

23. Hussein HA, Mekki BB, Abd El-Sadek ME, Ebd El Lateef E. Effect of L-Ornithine application on improving drought tolerance in sugar beet plants. Heliyon 2019;5:02631.

24. Çavuşoğlu D, Çavuşoğlu K. Role of exogenous 1-ornithine on physiological and cytogenetical parameters in Allium cepa L. exposed to salinity. 9th International symposium on ecology and environmental problems, 2019; 01-03 November 2019, Antalya, Turkey.

25. Li Y, Sun R, Yu J, Saravanakumar K, Chen J. Antagonistic and biocontrol potential of Trichoderma asperellum ZJSX5003 against the maize stalk rot pathogen Fusarium graminearum. Indian J Microbiol 2016;56:318-27.

26. Chao W, Wen-Ying Z. Evaluating effective Trichoderma iso- 
lates for biocontrol of Rhizoctonia solani causing root rot of Vigna unguiculata. J Integ Agric 2019;18:2072-9.

27. Zhang F, Ge H, Zhang F, et al. Biocontrol potential of Trichoderma harzianum isolate T-aloe against Sclerotinia sclerotiorum in soybean. Plant Physiol Biochem 2016;100:64-74.

28. Palaniappan K, Holley R. Use of natural antimicrobials to increase antibiotic susceptibility of drug resistant bacteria. Int J Food Microbiol 2010;140:164-8.
29. Khaledi N, Taheri P, Tarighi S. Antifungal activity of various essential oils against Rhizoctonia solani and Macrophomina phaseolina as major bean pathogens. J Appl Microbiol 2014;118:704-17.

30. Della Pepa T, Elshafie HS, Capasso R, et al. Antimicrobial and phytotoxic activity of Origanum heracleoticum and O. majorana essential oils growing in Cilento (Southern Italy). Molecules 2019;24:2576. 